See Article page 1847.

\section{Commentary: Concomitant atrial fibrillation ablation: The juice is worth the squeeze}

\author{
J. Hunter Mehaffey, MD, MSc, and \\ Robert B. Hawkins, MD, MSc
}

In this issue of the Journal, Bakir and colleagues ${ }^{1}$ present a propensity-matched analysis of patients with versus those without concomitant Cox-Maze IV (CMP-IV) ablation for atrial fibrillation (AF). Their primary outcomes of interest were acute kidney injury (AKI) and renal failure. In a well-balanced cohort with 308 patients in each group, the authors demonstrate a higher incidence of AKI ( $32 \%$ vs $16 \% ; P<.001)$ based on The Kidney Disease Improving Global Outcomes (KDIGO) classification. After further risk adjustment with regression modeling to adjust for operation and cross-clamp time, CMP-IV was still independently associated with AKI (odds ratio, 1.89; $P=.017$ ). The authors go on to demonstrate that patients with perioperative AKI have worse medium-term survival $(P<.001)$, at a median follow-up of 3 years. However, this effect was overcome by the survival benefit of CMP-IV $(P=.001)$ in this cohort of patients with preoperative AF.

This work builds on previous research from this well-known group at Washington University exploring the incremental risk of concomitant CMP-IV for patients undergoing cardiac surgery with preoperative AF. Their 2013 study demonstrated no increased operative mortality despite longer cross-clamp times. ${ }^{2}$ Rankin and colleagues ${ }^{3}$ took this one step further, using the Society of Thoracic Surgeons (STS) National Adult Cardiac Surgery Database and reporting reduced risk-adjusted operative mortality

\footnotetext{
From the Division of Thoracic and Cardiovascular Surgery, University of Virginia, Charlottesville, Va.

Disclosures: The authors reported no conflicts of interest.

The Journal policy requires editors and reviewers to disclose conflicts of interest and to decline handling or reviewing manuscripts for which they may have a conflict of interest. The editors and reviewers of this article have no conflicts of interest.

Received for publication Jan 19, 2021; revisions received Jan 19, 2021; accepted for publication Jan 21, 2021; available ahead of print Jan 29, 2021.

Address for reprints: J. Hunter Mehaffey, MD, MSc, Department of Thoracic and Cardiovascular Surgery, PO Box 800679, Charlottesville, VA 22908-0709 (E-mail: jhm9t@virginia.edu).

J Thorac Cardiovasc Surg 2022;164:1861-2

$0022-5223 / \$ 36.00$

Copyright (c) 2021 by The American Association for Thoracic Surgery

https://doi.org/10.1016/j.jtcvs.2021.01.077
}

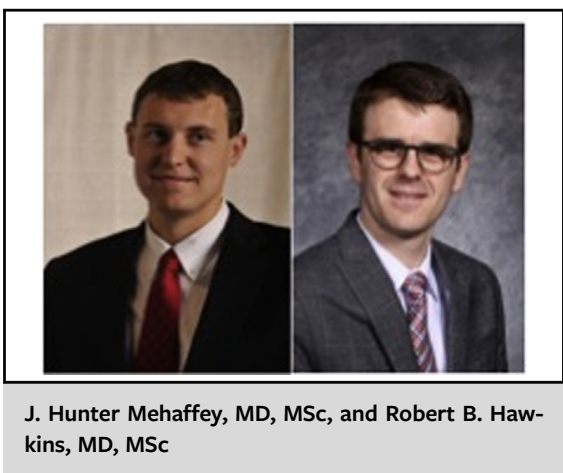

CENTRAL MESSAGE
Concomitant Cox-Maze IV abla-
tion is associated with increased
acute kidney injury but superior
long-term survival in patients
with preoperative atrial fibrilla-
tion undergoing cardiac surgery.

with concomitant AF ablation during mitral valve surgery. ${ }^{3}$

Several retrospective studies have examined the issue of increased morbidity associated with additional procedures, but this study provides valuable information on renal-related complications. It is believed that renal injury is related to the increased cross-clamp and cardiopulmonary bypass times, but an independent association between CMP-IV and AKI remains even after adjusting for these factors in regression modeling on the matched data. The authors suggest ablation-induced cardiac necrosis and release of inflammatory mediators or cytokines as areas of future research into the mechanism of AKI with CMP-IV.

Another important finding of this study paper is that $57 \%$ of patients with preoperative AF did not undergo concomitant AF ablation. The 2017 STS clinical practice guidelines recommend concomitant $\mathrm{AF}$ ablation during mitral valve surgery, with the strongest level of evidence (level 1A) based on randomized controlled data from the Cardiothoracic Surgical Trials Network study demonstrating a survival benefit. ${ }^{4,5}$ Although the present study included patients undergoing all types of cardiac surgery with dates spanning 2008 to 2018 , the rate of $57 \%$ is lower than expected from a high-quality center of excellence for AF ablation. Previous work by our group has demonstrated wide variability in the rate of concomitant $\mathrm{AF}$ ablation during mitral valve surgery in a contemporary statewide cohort despite STS guidelines. ${ }^{6}$ The present study provides 
important data to support the long-term benefit despite a small increased short-term risk associated with the additional procedure.

\section{References}

1. Bakir NH, Khiabani AJ, MacGregor RM, Kelly MO, Sinn LA, Schuessler RB, et al. Concomitant surgical ablation for atrial fibrillation is associated with increased risk of acute kidney injury but improved late survival. J Thorac Cardiovasc Surg. 2022;164:1847-57.e3.

2. Saint LL, Damiano RJ Jr, Cuculich PS, Guthrie TJ, Moon MR, Munfakh NA, et al Incremental risk of the Cox-maze IV procedure for patients with atrial fibrillation undergoing mitral valve surgery. J Thorac Cardiovasc Surg. 2013;146:1072-7.
3. Rankin JS, Grau-Sepulveda MV, Ad N, Damiano RJ Jr, Gillinov AM, Brennan JM, et al. Associations between surgical ablation and operative mortality after mitral valve procedures. Ann Thorac Surg. 2018;105:1790-6.

4. Badhwar V, Rankin JS, Damiano RJ Jr, Gillinov AM, Bakaeen FG, Edgerton JR, et al. The Society of Thoracic Surgeons 2017 clinical practice guidelines for the surgical treatment of atrial fibrillation. Ann Thorac Surg. 2017;103:329-41.

5. Gillinov AM, Gelijns AC, Parides MK, DeRose JJ Jr, Moskowitz AJ, Voisine P, et al. Surgical ablation of atrial fibrillation during mitral-valve surgery. $N$ Engl J Med. 2015;372:1399-409.

6. Mehaffey JH, Krebs E, Hawkins RB, Charles EJ, Tsutsui S, Kron IL, et al. Variability and utilization of concomitant atrial fibrillation ablation during mitral valve surgery. Ann Thorac Surg. 2021;111:29-34. 